\title{
Educomunicación, televisión y valores. Análisis de la programación desde una óptica publicitaria
}

\author{
Rodrigo Elías Zambrano \\ Universidad de Cádiz (España)-Rodrigo.elias@uca.es \\ Gloria Jiménez-Marín \\ Universidad de Sevilla (España) - gloria_jimenez@us.es \\ Irene García Medina \\ Glasgow Caledonian University (United Kingdom) \\ irene.garcia2@gcu.ak.uk
}

\section{Resumen}

Entender la televisión como un mero ente de entretenimiento es un concepto obsoleto. La tradicional definición de los medios de comunicación con una finalidad informativa también queda pequeña. En pleno siglo XXI damos un paso más: afirmamos que, además de informar y entretener, los medios, y en el caso que nos ocupa, la televisión, forma. Educa. Por ello, partimos de la revisión de la literatura existente para, a partir de una óptica publicitaria, hacer un análisis de la programación centrándonos en un par de casos comparables concretos en la televisión española. Y observamos como ello afecta a la estrategia de medios publicitarios.

Palabras clave: educomunicación; publicidad; medios; televisión.

\section{Educocomunicação, televisão e valores.}

Análise da grade a partir de uma perspectiva de publicidade

\section{Resumo}

Compreender a televisão como uma mera entidade de entretenimento é um conceito obsoleto. A definição tradicional da mídia com um propósito informativo também é pequena. No século XXI, damos um passo adiante: afirmamos que, além de informar e divertir, a mídia e, no caso que nos in- 
teressa, a televisão, forma. Educa. Portanto, começamos a partir da revisão da literatura existente, a partir de uma perspectiva de publicidade, para fazer uma análise da grade focada em alguns casos concretos comparáveis na televisão espanhola. E observamos como isso afeta à estratégia dos meios publicitários.

Palavras-chave: educomunicação; publicidade; significa; televisão.

\title{
Educommunication, television and values. Anal- ysis of the programming from an advertising per- spective
}

\begin{abstract}
Understanding television as a mere entertainment entity is an outdated concept. The traditional definition of the media with an informative purpose is also small. In the XXI century we take a step further: we affirm that, in addition to informing and entertaining, the media, and in the case that concerns us, television, form. Educate. Therefore, we start from the review of the existing literature, from an advertising perspective, to make an analysis of the grid focusing on a couple of comparable concrete cases in Spanish television. And we see how this affects the strategy of advertising media.
\end{abstract}

Keywords: educommunication; advertising; media; television;

\section{Introducción}

La televisión, como medio de comunicación, no se limita a representar la realidad social, sino que ayuda a construirla; ayuda al labor de formación personal. Sostiene Wolton (1997) que la principal característica del medio televisivo reside en su capacidad de unión entre las experiencias individuales y las colectivas. De esta forma, existen programas de televisión que buscan equilibrar esos vacíos y promueven nuevos valores sociales apoyando una evolución en los comportamientos en base al nuevo orden social. Es el caso de algunos programas de las televisiones públicas en España (nacional y autonómicas), porque, autores como Lacalle (2001, p. 21) defienden que

[...] la televisión asume actualmente competencias que tradicionalmente llevaban a cabo las instituciones y se ha convertido en una especie de 
panóptico del mundo, sin ningún tipo de obstáculos a la mirada de un espectador que es a la vez observador y observado; que utiliza el escenario televisivo para ver y ser visto.

Por ello, podemos afirmar que a lo largo de nuestra vida seguimos formándonos y haciendo evolucionar nuestros conocimientos y los valores que consideramos propios, más allá de la formación y educación estrictamente reglada a través de la escuela o la universidad. A veces de manera intencionada, a veces de manera libre, del mismo modo que los niños aprendían valores sociales con programas educativos como "Barrio Sésamo" - o las personas de cualquier edad aprenden idiomas a través del cine o la televisión en versión original (JIMÉNEZ-MARÍN; ELÍAS ZAMBRANO, 2012). Y, en este aspecto, la televisión es un elemento fundamental.

\section{Metodología}

En nuestro caso en el ámbito concreto de la presente investigación, acudimos a la observación sistemática: observamos desde un punto de vista externo, registramos ciertas situaciones y las analizamos con posterioridad, siguiendo las indicaciones de González (1997), de una manera exploratoria y descriptiva. Así, nosotros proponemos una comparativa entre un programa de La Tarde y otro de Sálvame Limón, como polos opuestos en una misma programación.

Dentro de esta observación sistemática, establecemos dos partes muy diferenciadas: Una primera observación que, aunque realizada de manera metódica, bien es cierto que es prolongada en el tiempo. Esta observación extendida consiste en el reconocimiento de la influencia de determinados programas o personajes televisivos en la población, en este caso, andaluza. Concretamente, durante el período 2003-2016, observamos mediante conversaciones con personas mayores de ciudades y pueblos de distintas partes de Andalucía, la importancia de espacios televisivos en sus vidas diarias. Nos referimos a programas de la misma cadena que seguían una fórmula parecida y al presentador en cuestión.

La Tarde es el único espacio donde una persona mayor anónima es invitada para hablar de su vida y centra la atención del programa. Y 
esto les provoca empatía según hemos podido observar y escuchar de sus testimonios.

En la presente investigación, dado que la técnica de la observación es aquí empleada para poder aplicar el método del estudio de caso único, debemos reseñar que la muestra observada es el propio programa La Tarde. Los aspectos a observar son los siguientes: Manifestaciones sobre la igualdad de género, expresiones acerca del respeto a los mayores, valoraciones sobre la evolución del comportamiento social, referencias históricas, referencias lingüísticas, aspectos negativos (críticas, exposición pública ...), aspectos empresariales que influyan en la función educativa del programa (organigrama, personal, funciones, motivaciones...).

Esta técnica la concretamos en un programa de La Tarde correspondiente al mes de mayo de 2016.

Por último, y como complemento a este análisis del programa $L a$ Tarde, realizamos también, por comparativa, un análisis observacional de un programa televisivo que compite directamente con La Tarde en tipología de público, fecha y horario de emisión como es el programa Sálvame Limón.

\section{Análisis y discusión de resultados}

Desde el punto de vista del desarrollo y la creación del programa, se observan varios elementos que influyen en su posterior contenido educativo. En primer lugar, el respeto por las personas mayores se aprecia como un elemento esencial. Se comunica a los nuevos trabajadores, se recuerda con carteles en la redacción y marca la organización del equipo humano y técnico. La prioridad en la producción son los invitados, a los que se les realiza un prolongado seguimiento telefónico previo (durante semanas en muchos casos) y se les acompaña permanentemente durante el día de asistencia al programa.

Ese respeto por los participantes, especialmente por las personas mayores, también se observa en el tratamiento de la información, pese a que en ocasiones, cuando el tono general del programa se vuelve distendido y jocoso, pueda resultar discutible.

A través del visionado de los programas, pueden apreciarse expresiones referentes a momentos históricos, cuando los invitados cuentan 
parte de sus vidas y relatan como se vivían en esas épocas. Para ello, el equipo de redacción suele pedir a los invitados material audiovisual que ayude a ilustrar esas historias. $\mathrm{Al}$ ser normalmente, personas de más de 60 años, ese material suele ser fotográfico.

También se observa un sutil fomento del buen uso del lenguaje a través de las correcciones lingüísticas que el presentador realiza a los invitados. Suele no ser muy evidente por la diplomacia con la que se realiza, pero se aprecia a menudo. Además de una función didáctica, al utilizar sinónimos de los vocablos que pueden no entenderse bien por la mayoría del público, tiene otra función práctica, ya que facilita que la audiencia pueda entender el significado y seguir el discurso del programa.

Respecto a las relaciones hombre-mujer, se observa una defensa explícita de la igualdad entre géneros. En el discurso del programa no se emplean ni se permiten expresiones machistas ni lesivas hacia la mujer. En alguna ocasión, el presentador ha corregido al invitado si este se ha expresado en esos términos. Además, en la sección informativa Actualidad es frecuente la elección de noticias sobre violencia de género, que son difundidas a modo de denuncia. Se facilitan las recomendaciones institucionales al respecto y se informa de forma constante sobre sus derechos y el teléfono 016 de violencia contra la mujer, animando a su utilización y a la lucha contra este fenómeno.

Desde un punto de vista general de los elementos educativos, observamos que las únicas secciones que han permanecido siempre en el programa son las de En Compañia y Actualidad, esto es: la que se ocupa de servir de plataforma para que las personas que están solas se conozcan, y la que contiene las noticias del momento que pueden interesar al público de $L a$ Tarde. Además de éstas, por el programa han pasado otras de reporterismo o musicales, que con el tiempo se han ido suprimiendo. Pero, como hemos podido observar, los aspectos educativos del programa se encuentran repartidos básicamente entre estas dos secciones, y en la manera de transmitir conocimientos y valores en relación a la soledad de las personas.

Por su parte, en contraposición, encontramos a Sálvame Limón. Este programa comienza presentando (de forma dramática) un conflicto de partida: los posibles problemas económicos y laborales de una de sus 
colaboradoras, Rosa Benito. Observamos cómo ya de partida se da el fenómeno antes descrito. La noticia de apertura del programa, y por tanto la que se supone es la más interesante del día, es un rumor sobre un miembro del equipo, que además plantea cuestiones con las que claramente la audiencia puede identificarse: los problemas económicos y la búsqueda de empleo, además de su situación sentimental.

Al terminar la telepromoción se da paso a un corte publicitario precedido por otro vídeo-cebo sobre otro conflicto. En este caso sobre el divorcio del tenista Feliciano López y la modelo Alba Carrillo. En el se habla de los aspectos como el rencor, el engaño, las posibles infidelidades o los casamientos obligados a través de expresiones como "vende despecho", "ella ya lo sabía", "Feliciano nunca quiso casarse" o "¿Hay terceras personas?”. A la vuelta de publicidad, tras una nueva emisión del citado cebo inicial, nos ofrecen otra telepromoción.

Después del inicio descrito anteriormente, en el que dominan los contenidos publicitarios junto a algunos avances de contenidos, Sálvame vuelve al tema presentado en el comienzo, el supuesto nuevo trabajo de la colaboradora Rosa Benito, con la emisión de un vídeo en el que otros colaboradores del programa afirman que trabaja en un bingo (lo llaman "sala de ocio [...] con muchos cartones") mientras ella lo niega. Es representativo como resuelven técnicamente el momento, ya que la emisión de dicho vídeo se realiza la pantalla partida, esto es, pudiendo ver las dos imágenes a la vez. Por un lado las acusaciones y afirmaciones con las supuestas pruebas sobre el asunto. Y por otro, un primer plano de la protagonista del conflicto para que el telespectador no se pierda ningún gesto que pueda hacer al escuchar lo que otros dicen de ella al mismo tiempo que la audiencia. Como puede observarse, la historia se reduce a aseveraciones de unos colaboradores contra el desmentido de otra colaboradora. Pero al dársele un tratamiento narrativo apropiado, basado entre otros elementos en la fragmentación de los contenidos y en el uso de señuelos informativos, consigue captar la atención de la audiencia.

Conviene subrayar aquí la aparición de algunos aspectos interesantes para la comparación entre programas que nos atañe. En su desmentido, Benito habla abiertamente (a cambio de dinero, conviene recordar) 
de sus problemas económicos y los de su hijo, y de sus deudas con Hacienda, nombrando pagos del "[...] colegio de su hijo, la luz, el teléfono, comida[...]". Cuestiones personales que normalmente los individuos se reservan para hablarlas con su círculo más íntimo a no ser que haya una motivación especial para darlas a conocer en público. Pero en este caso, en nuestra observación no alcanzamos a ver ningún motivo para hacerlo (ya que no existe una demanda social de información sobre el tema ni afecta de forma directa la población alguna) más allá de la construcción de un conflicto que, de forma artificial a través de los guiones de los programas, pasa de problema personal a cuestión pública seguida por miles de personas en directo cada tarde.

Por el contrario, sobre este aspecto de la aportación de datos y la narración a los telespectadores de circunstancias personales, observamos como en La Tarde también aparece numerosa información al respecto, si bien la finalidad que se aprecia es bien distinta. En este caso el objetivo es rememorar de forma resumida sus vidas para que la audiencia pueda conocerlos (dentro de la brevedad que exige el formato televisivo) y que, a través de este primer contacto, algunas personas que los estén viendo se identifiquen con ellos o se sientan agradados y se animen a llamar al programa para, posteriormente, poder hablar con ellos por teléfono y tener la posibilidad de conocerlos en persona con el objetivo ya descrito de acabar con la soledad de ambos. Estamos pues ante una propuesta en la que se busca la mejora en la vida de dos personas que se reconocen necesitadas de ayuda. Y en la que ninguna de ellas recibe contraprestación económica alguna, por lo que el beneficio monetario de la acción se reduce al evidente negocio empresarial de la productora (como cualquier otra entidad privada), no a los protagonistas como sí ocurre en Sálvame.

En La Tarde, sin embargo, no apreciamos esa "endogamia”, ya que los presentadores ni los colaboradores son sustituidos por sus familiares. Y, respecto a los contenidos, aunque es cierto que dentro de la narración de diferentes sucesos de sus vidas, los invitados frecuentemente incluyen conflictos con personas de su familia y situaciones en las que critican a parte de su entorno, puede entenderse como inevitable para describir dichas vivencias. Además, según nuestra observación, el presentador del programa no suele 
insistir en temas conflictivos o dolorosos para el invitado, sino más bien al contrario, saltando a otras preguntas ante momentos en los que estos de emocionan o muestran sufrimientos. En contraposición, en Sálvame observamos como se busca la explotación de conflictos y emociones, llegando en ocasiones sus mismos colaboradores a las lágrimas, como ocurre con Chelo García Cortés en el minuto 42 de Sálvame Limón. En ese momento, ante acusaciones de ser conflictiva y repudiada por algunos de sus compañeros guionistas (lo que motivó presuntamente que se pusieran en huelga contra ella), amaga con romper a llorar al, aparentemente, emocionarse ante las cámaras. Si bien varios de los colaboradores la animan y defienden y el público le aplaude (bajo indicaciones del regidor para ello), otros ríen ante este hecho y el programa, en vez de pasar a otro asunto, continúa con ello varios minutos preguntándole "cómo se siente" ahondando en sus sentimientos antes de hacer una pausa "para que se recupere" emocionalmente. Además, pasados unos minutos, el segundo bloque del programa comienza con la continuación de este conflicto, lo que demuestra el carácter unitario del programa pese a su división en dos. Con frecuencia hay gritos e interrupciones entre varios tertulianos que se alargan durante más de 2 minutos de forma casi continuada dificultando el visionado del programa, apreciándose a la vez enfados y sonrisas entre ellos (hecho que observamos repetidas veces a lo largo del espacio televisivo).

Otro aspecto reseñable es el siguiente tema a tratar en Sálvame: los problemas del conocido periodista Jesús Quintero, que es presentado diciendo que "siempre es un hombre polémico". Sobre él se discute si tiene problemas económicos, si es buen pagador y si trata mal a sus trabajadores. $\mathrm{Y}$ sobre ello se vierten opiniones encontradas, unas a favor y otras en contra, lo que facilita el debate (aunque quizá por el tono agresivo del programa sería más apropiado hablar al menos de discusión, si no de pelea) durante el cual los comentaristas se insultan, se gritan, se interrumpen, se levantan de sus asientos y caminan libremente por el plató, incluso saliendo de él. Resulta llamativo como, comenzando con los citados insultos, enseguida dejan de lado los comentarios sobre el "famoso real", el señor Quintero, del que hablarán solamente unos segundos, para pasar a pelearse entre ellos. Transcurridos más de 6 minutos de discusiones entre distintos 
colaboradores, sobre el minuto 40 se producen afirmaciones como que "[...] la huelga de guionistas (del programa) fue totalmente inventada [...]" , a lo que responde el director en persona que "[...] la huelga, lo único que hicimos fue pararla [...]. Ella (Chelo García Cortés) había cosas que no estaba dispuesta a hacer, y entonces dificultaba el trabajo de los guionistas [...]". Se reconoce aquí la figura y el trabajo del equipo de guión de Sálvame, responsables de idear, estructurar y desarrollar las historias que se narran cada día. Y, credibilidades aparte, aparece otra duda sobre una posible manipulación de las tramas del programa, que de nuevo alimenta lo que a nuestro entender es el motor de este espacio: la creación de constantes conflictos y su inteligente gestión con y para la audiencia.

Sobre el tratamiento que se le da al tema de la igualdad de géneros, en el programa Sálvame analizado apreciamos una situación llamativa. Cuando hablan acerca de la ruptura de la relación del tenista Feliciano López y la modelo Alba Carrillo, no ocurre como con el tema de Jesús Quintero, ya que sí que se le dedica bastante tiempo. Durante unos 16 minutos, los numerosos colaboradores opinan al respecto (unos a favor de él y otros a favor de ella) y recuerdan antiguas situaciones relacionadas con los protagonistas, si bien no se aporta ninguna información ni sus declaraciones, sino opiniones y conjeturas. Acerca de la relación, desde el programa se vierten acusaciones de que la modelo y su madre presionaban al deportista para que abandonase el tenis. Ante esto, uno de los colaboradores afirma en el minuto 38 de este segundo bloque que eso no puede ser cierto, ya que "de qué van a vivir", dando por hecho la dependencia económica de la pareja respecto del trabajo de él, pese a que Carrillo es, además de modelo y colaboradora de televisión en activo, diseñadora de moda, transmitiendo así valores poco igualitarios respecto al género. Ninguno de sus compañeros, de los que seis son mujeres, corrige o discute su comentario sexista.

También nos resulta importante el tratamiento observado en cuanto a la narración de las frecuentes circunstancias de penurias económicas por parte de los invitados, que suelen estar dominadas por el respeto, la empatía y, a veces, el difícil pero exitoso empleo del humor con gran delicadeza por parte del presentador para 'quitar hierro' al asunto y descargar 
de tensión la situación. Nos parece trascendente insistir que, por lo observado, no supone en absoluto una falta de respeto sino todo lo contrario, ya que el invitado claramente suele agradecer ese contrapunto chistoso que se le añade a su historia. Así, por ejemplo, cuando en este programa Magdalena cuenta que se casó con el traje de su hermana o que el consiguiente banquete lo organizaron de forma que todos los invitados llevaran algo para disfrutar en común en el campo, los comentarios del presentador son de absoluta aprobación y defensa de ese procedimiento, quitándole importancia al hecho de no poder seguir las costumbres sociales por motivos económicos.

En ambos espacios los telespectadores tienen una presencia importante, ya que gozan de algunos momentos habilitados para expresar sus opiniones y que estas sean escuchadas durante la emisión, pero encontramos importantes diferencias en cuanto a su tratamiento. Por una parte, en Sálvame no se permite la entrada de llamadas en directo, sino que se emiten vídeos con una serie de mensajes previamente filtrados y elegidos por el programa, además de editados. Respecto al contenido de los mismos, los comentarios encontrados en nuestro análisis han resultado en su mayoría críticas y juicios emitidos sobre los temas tratados que son utilizados para generar en el plató nuevas polémicas y discusiones.

En La Tarde, sin embargo, la audiencia no tiene ningún espacio para expresarse acerca del programa de forma general, pero sí reciben a diario llamadas en directo de las personas interesadas en conocer a los invitados que están solos y buscan compañía. De todas las llamadas recibidas por cada invitado, el equipo del programa selecciona una de ellas en base a los requisitos mencionados durante la entrevista (normalmente edad, características personales básicas, aficiones, etc.), y la persona elegida habla en directo con el invitado en plató, suponiendo un primer contacto entre ellos. Este proceso se repite con cada una de las personas que asisten a la sección En compañía se vive mejor de La Tarde.

Debido a la importante diferencia de formato y target entre los dos programas que estamos comparando, hemos observado en nuestro análisis varios aspectos en los que no encontramos paralelismos claros en ambos pero que nos parecen destacables para entender las diferencias 
entre ellos. Así, respecto a Sálvame, conviene señalar que su figura de La defensora de la audiencia no va encaminada a proteger los derechos de los espectadores como suele suceder en otras televisiones, sino que se trata simplemente del papel de conductora de un espacio para dar a la audiencia la posibilidad de opinar sobre los temas que se tratan y que sus comentarios se escuchen públicamente.

Para finalizar el programa, se realiza un repaso a otros temas de actualidad social utilizando contenidos de otro espacio de la cadena, en este caso de El programa de Ana Rosa, así como comentarios sobre la antigua ganadora del concurso Gran Hermano 15, también ofrecido por Telecinco. Observamos así de nuevo la retroalimentación que realizan los diferentes programas de los canales del grupo Mediaset. Sin embargo, en La Tarde lo que encontramos son elementos culturales e informativos (referidos a la actualidad general) inexistentes en Sálvame.

\section{Discusión}

Estudiados y analizados ambos programas y su entorno y hecha una revisión literaria encontramos una gran cantidad de puntos en común entre la tradicional educomunicación aplicada a la escuela, la enseñanza escolar, y el punto de vista del que partimos para la investigación: la educación a través de la televisión pero, en este caso, educación en valores dirigida a los adultos.

La Tarde es un programa que ayuda a gente en soledad, anima a romper tabúes y a cambiar valores socioculturales, además de facilitar contactos entre interesados. Intercede entre los protagonistas, les asesora y aconseja, así como ayuda a que se hagan realidad ilusiones/sueños de los interesados. Este programa realiza un seguimiento serio y continuado de los invitados y sus experiencias.

Su propia filosofía de empresa, que se muestra a través de la seriedad, respeto y profesionalidad del programa.

Por contra, Sálvame, es un programa que remarca estereotipos, impulsa insultos, no aporta información relevante y en cambio sí contenidos vacíos... La diferencia entre uno y otro y programa, a nivel de valores, resulta significativa y digna de destacar. No obstan- 
te, ambos lanzan un modelo educacional: en un caso, uno positivo; en otro, negativo.

Y con ello la publicidad encuentra la segmentación perfecta de su público objetivo, de una manera fácil y rápida. Con ello, la perspectiva publicitaria encuentra en estos dos modelos dispares educativos una herramienta de planificación de medios perfecta.

\section{Referencias}

GERVER, R. Creando hoy las escuelas del mañana: la educación y el futuro de nuestros hijos. Madrid: SM, 201

GONZÁLEZ, M. J. Metodología de la investigación social. Técnicas d recolección de datos. Alicante: Aguaclara, 1997.

JIMÉNEZ-MARÍN, G.; ELÍAS ZAMBRANO, R. Publicidad en 35 películas. El cine como instrumento para la formación en la Universidad. Aularia, 2012.

JIMÉNEZ-MARÍN, G.; PÉREZ CURIEL, C.; ELÍAS ZAMBRANO, R. Del valor educativo de los medios de comunicación: una aproximación al caso audiovisual. Ámbitos, Sevilla, n. 25, p. 22-36, 2014.

LACALLE, C. El espectador televisivo. Los programas de entretenimiento. Barcelona: Gedisa, 2001.

MEDRANO, C. ¿Se puede favorecer el aprendizaje de valores a través de las narraciones televisivas? Revista de Educación, v. 338, p. 245-270, 2008.

ROBINSON, K. Fuera de nuestras mentes: Aprender a ser creativo. [S.1.]: Capstone Editorial, 2001.

WOLTON, D. Penser la communication. París: Flammarion. 1997.

Dados dos autores

Rodrigo Elías Zambrano - Universidad de Cádiz (España) - Rodrigo.elias@uca.es Dr. en Comunicación y Ldo. en Comunicación auidiovisual por Universidad de Sevilla. Máster en Comunicación y educación audiovisual por Universidad de Huelva. Máster en Gestión de empresas audiovisuales por Universidad de Sevilla.

Gloria Jiménez-Marín - Universidad de Sevilla (España) - gloria_jimenez@us.es Dra. en Comunicación, Lda. en Periodismo y Lda. en Publicidad y RR.PP. por Universidad de Sevilla. 
Irene García Medina - Glasgow Caledonian University (United Kingdom) irene.garcia2@gcu.ak.uk

Lda. en CC. de la Información por Universidad Complutense de Madrid, Dra. en Marketing por Université Sophia Antipolis, Dra. en Relaciones internacionales por Universidad de Viena.

Submetido em: 28-2-2018

Aceito em: 31-3-2018 